\title{
Pretreatment platelet-lymphocyte ratio is an independent predictor of cervical cancer recurrence following concurrent chemoradiation therapy
}

\author{
KEIICHIRO NAKAMURA, TAKESHI NISHIDA, TOMOKO HARUMA, JUNKO HARAGA, CHIAKI OMICHI, \\ CHIKAKO OGAWA, TOMOYUKI KUSUMOTO, NORIKO SEKI, HISASHI MASUYAMA and YUJI HIRAMATSU \\ Department of Obstetrics and Gynecology, Okayama University Graduate School of Medicine, \\ Dentistry and Pharmaceutical Sciences, Okayama, Okayama 700-8558, Japan
}

Received February 24, 2015; Accepted June 22, 2015

DOI: $10.3892 / \mathrm{mco} .2015 .595$

\begin{abstract}
The aim of the present study was to identify the correlations between inflammation markers such as neutrophil-lymphocyte ratio (NLR), platelet-lymphocyte ratio (PLR) and C-reactive protein (CRP) and the prognosis in patients with recurrent cervical cancer. The associations among NLR, PLR and CRP and clinical characteristics and prognosis were examined in 32 patients receiving chemotherapy with recurrent cervical cancer following concurrent chemoradiation therapy (CCRT). The patient median survival time was 198 days (range, 42-1,022 days). Pretreatment NLR and PLR were significantly correlated with the recurrence of cervical cancer following CCRT $(\mathrm{R}=-0.538, \mathrm{P}=0.002$; and $\mathrm{R}=-0.542$, $\mathrm{P}=0.001$, respectively). Pretreatment PLR $>322.0$ was significantly associated with a poor prognosis for recurrent cervical cancer following CCRT by univariate and multivariate analyses $(\mathrm{P}=0.015$ and $\mathrm{P}=0.029)$. These findings indicate that pretreatment PLR is an important predictor of prognosis in patients with recurrent cervical cancer following CCRT.
\end{abstract}

\section{Introduction}

Cervical cancer is the second most common gynecological malignancy (1). Concurrent chemoradiation therapy (CCRT) with platinum-based chemotherapy has been established as the standard of care for patients with stage IB2-IVA cervical cancer [International Federation of Gynecology and Obstetrics (FIGO) classification] $(2,3)$. However, the recurrence rate of cervical cancer varies between 11 and $22 \%$

Correspondence to: $\mathrm{Dr}$ Keiichiro Nakamura, Department of Obstetrics and Gynecology, Okayama University Graduate School of Medicine, Dentistry and Pharmaceutical Sciences, 2-5-1 Shikata-cho, Okayama, Okayama 700-8558, Japan

E-mail: k-nakamu@cc.okayama-u.ac.jp

Key words: recurrent cervical cancer, platelet to lymphocyte ratio, prognosis predictor in FIGO stage IB-IIA and between 28 and 64\% in FIGO stage IIB-IVA (4).

Inflammation has been shown to enable various cancer characteristics, thus affecting prognosis. Recent evidence has indicated that relative differences in neutrophil, platelet and lymphocyte counts, and neutrophil-lymphocyte ratio (NLR) and platelet-lymphocyte ratio (PLR) are systemic indicators of prognosis (5). C-reactive protein (CRP) also increases under inflammation in cancer (6). Pretreatment measurements of peripheral blood NLR, PLR and CRP are independent predictors of a poor prognosis in various types of cancer (7-12). However, their predictive role in recurrent cervical cancer is unknown. In the present study, the associations among NLR, PLR and CRP and the clinical characteristics and prognoses of patients with recurrent cervical cancer following CCRT were investigated.

\section{Materials and methods}

Study subjects. The clinicopathological characteristics of 32 patients with recurrent cervical cancer who had been treated in the Department of Obstetrics and Gynecology of Okayama University Hospital (Okayama, Japan) between April 2005 and June 2014 were retrospectively analyzed. The primary treatment of these patients was CCRT. All the patients were treated with a combination of external irradiation (50 Gy administered in 25 fractions over 5 weeks; 4 -field box technique) and high-dose intracavitary brachytherapy (24 Gy/4 times); and concurrent chemotherapy of either cisplatin $\left(40 \mathrm{mg} / \mathrm{m}^{2}\right.$ infusion weekly for 6 cycles) or nedaplatin $\left(30 \mathrm{mg} / \mathrm{m}^{2}\right.$ infusion weekly for 8 cycles). Following the primary treatment, the patients underwent follow-up examinations approximately every 1-2 months for the first 6 months, and subsequently, every 3 months for the next 2 years. The study protocol was approved by the Institutional Review Board of Okayama University Hospital. Informed consent was obtained from all the patients.

Chemotherapy. The policy of the Department of Obstetrics and Gynecology requires a performance score $\leq 2$ (World Health Organization criteria) prior to initiating second-line 
chemotherapy, involving $60 \mathrm{mg} / \mathrm{m}^{2}$ TC-paclitaxel weekly and carboplatin [area under the plasma-concentration curve (AUC), 1.5] (Bristol-Myers Squibb, New York, NY, USA). Chemotherapy for recurrent disease was continued until complete response or progressive disease was observed. Third-line chemotherapy consisted of single-agent irinotecan (CPT-11; $70 \mathrm{mg} / \mathrm{m}^{2}$ weekly for 3 weeks followed by 1 week off; Yakult, Tokyo, Japan); and fourth-line chemotherapy was single-agent gemcitabine $\left(700 \mathrm{mg} / \mathrm{m}^{2}\right.$ weekly for 3 weeks followed by 1 week off; Eli Lilly and Co., Indiana, IN, USA). These patient objective responses were principally evaluated by the Response Evaluation Criteria in Solid Tumors (version 1.1).

$N L R, P L R$ and CRP. Each subject had a complete blood cell count and differential white blood cell counts recorded within 7 days prior to chemotherapy. NLR was defined as the absolute neutrophil count divided by the absolute lymphocyte count. PLR was defined as the absolute platelet count divided by the lymphocyte count (Bayer HealthCare, Diagnostics Division, Tarrytown, NY, USA). Serum CRP was measured by latex nephelometry (LT Auto Wako, Osaka, Japan).

Statistical analysis. Statistical analyses were performed using the Mann-Whitney U test for comparisons with controls and one-factor analysis of variance followed by Fisher's protected least significant difference test for all the pairwise comparisons. Receiver operating characteristic (ROC) curves were generated for pretreatment NLR, PLR and CRP to determine cut-off values that predicted survival for $<200$ days (i.e., approximately the median survival period of 198 days for patients in the present study) that yielded optimal sensitivity and specificity; patients were subsequently grouped by these cut-off values. Univariate and multivariate analyses were performed using Cox's proportional hazards model to identify biomarkers that predict survival following adjustment for the effects of known prognostic factors. Analyses used SPSS software version 20.0 (IBM Corp., Armonk, NY, USA). P $<0.05$ was considered to indicate a statistically significant difference.

\section{Results}

Patient characteristics and treatments. Histological type, duration of recurrence-free survival and recurrence sites are listed in Table I. Tumors that were simultaneously found inside and outside the previously irradiated area were treated as extra-irradiation areas. Among the patients with recurrent disease, $32(100 \%), 15(46.9 \%)$ and $4(12.5 \%)$ patients received second-, third- and fourth-line chemotherapy, respectively (Fig. 1A). Responses of patients who received second- to fourth-line chemotherapy are shown in Fig. 1B. Tumor response rate (RR) and disease control rate were 12.5 and $43.7 \%$ for second-line chemotherapy, 6.7 and $20.0 \%$ for third-line chemotherapy, and 0.0 and $25.0 \%$ for fourth-line chemotherapy, respectively. The median numbers of cycles of second-, third- and fourth-line chemotherapy received were 12 (range, 3-24), 8 (3-18) and 6 (2-12), respectively. Median survival time was 198 days (range, 42-1,022 days). Final chemotherapy regimens for the 32 patients were second-line for 17 patients (53.1\%), third-line for 11 (34.4\%) and fourth-line for 4 (12.5\%). Their mean survival periods were 178.9, 483.0
Table I. Patient and tumor characteristics.

\begin{tabular}{lc}
\hline Baseline characteristics & All patients \\
\hline Age at diagnosis, mean years (range) & $52.6(25-78)$ \\
Histology, n (\%) & \\
SCC & $27(84.3)$ \\
AD & $3(9.4)$ \\
ADSQ & $2(6.3)$ \\
TFI, n (\%) & \\
$\leq 6$ months & $10(31.2)$ \\
$7-12$ months & $18(56.3)$ \\
$\geq 13$ months & $4(12.5)$ \\
Recurrent site, $\mathrm{n}(\%)$ & \\
Prior-irradiation area & $18(56.3)$ \\
Extra-irradiation area & $11(34.3)$ \\
Extra + prior-irradiation area & $3(9.4)$ \\
\hline
\end{tabular}

SCC, squamous cell carcinoma; AD, adenocarcinoma; ADSQ, adenosquamous cell carcinoma; TFI, treatment-free interval.

and 493.5 days, respectively; thus patients whose final treatment was a second-line regimen had a significantly shorter survival time compared with those who reached third- and fourth-line regimens $(\mathrm{P}=0.001$ and $\mathrm{P}=0.001)$ (Fig. 1C).

NLR, PLR and CRP. Median pretreatment NLR, PLR and CRP in these patients were NLR, 6.36 (range, 1.44-20.63); PLR, 426.06 (range, 154.77-1,227.6); and CRP, $3.64 \mathrm{mg} / \mathrm{dl}$ (range, 0.01-15.2 mg/dl). Patient pretreatment NLR ( $\mathrm{R}=-0.538$, $\left.\mathrm{R}_{2}=-0.289, \mathrm{P}=0.002\right)$ and PLR $\left(\mathrm{R}=-0.542, \mathrm{R}_{2}=-0.294, \mathrm{P}=0.001\right)$ were significantly and inversely correlated with their survival time (Fig. 2A). Pretreatment NLR and PLR for patients whose final regimen was second-line were significantly higher compared with for patients who survived to thirdand fourth-line regimens $(\mathrm{P}=0.006, \mathrm{P}=0.007, \mathrm{P}=0.019$ and $\mathrm{P}=0.019$, respectively). However, $\mathrm{CRP}$ concentration showed no association with any line of chemotherapy (Fig. 2B).

Whether the cancer recurrence sites were correlated with NLR, PLR, CRP, treatment-free interval (TFI), final-line chemotherapy or survival period were examined. Recurrences in extra-irradiation areas were associated with lower final-line chemotherapy number $(\mathrm{P}=0.011)$ and shorter survival time $(\mathrm{P}=0.021)$. However, none of the inflammatory markers were correlated with the recurrence site (Fig. 3).

ROC curve analyses determined cut-off values for pretreatment NLR, PLR and CRP that predicted survival $<200$ days at NLR, 3.95 (AUC, 0.809; sensitivity $81.3 \%$; specificity $56.2 \%$ ); PLR, 322.0 (AUC, 0.816; sensitivity $81.3 \%$; specificity $68.7 \%$ ); and CRP, $0.7 \mathrm{mg} / \mathrm{dl}$ (AUC, 0.693; sensitivity 68.8\%; specificity $56.2 \%$ ) (Fig. 4).

Survival time analysis. Whether clinical factors correlated with survival $<200$ days was assessed by univariate and multivariate analyses. Univariate analyses were significantly associated with extra-irradiation area $(\mathrm{P}=0.009)$, second-line chemotherapy as final-line chemotherapy $(\mathrm{P}=0.003)$ and 

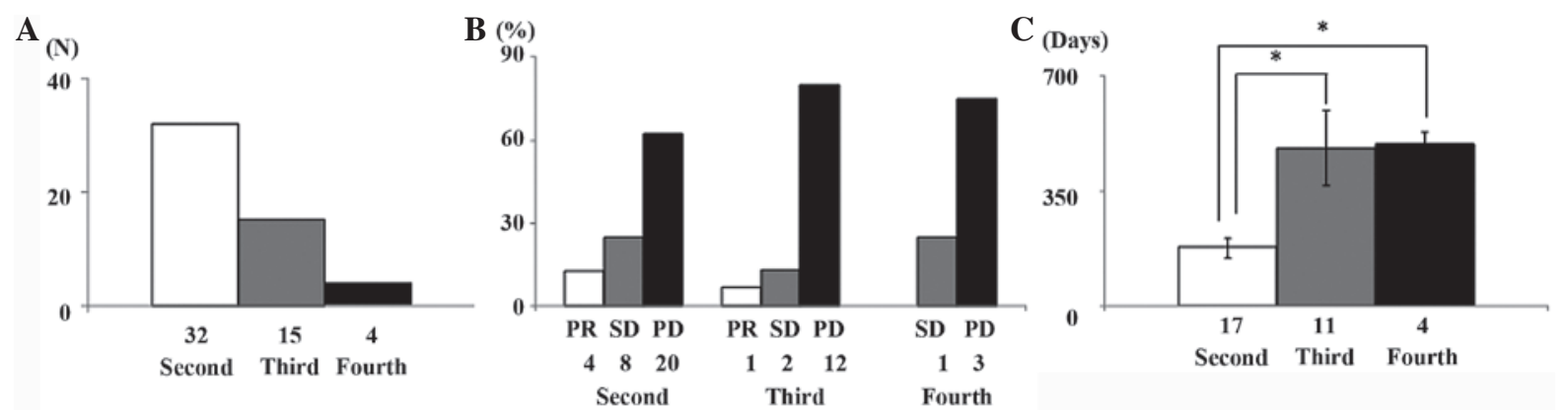

Figure 1. (A) Number of patients who received second- to fourth-line chemotherapy regimens for recurrent cervical cancer following first-line concurrent chemoradiation therapy. (B) Responses to second- to fourth-line regimens in these patients. (C) Survival time for these patients by their final chemotherapy lines. PR, partial response; SD, stable disease; PD, progressive disease. ${ }^{*} \mathrm{P}<0.05$.

A
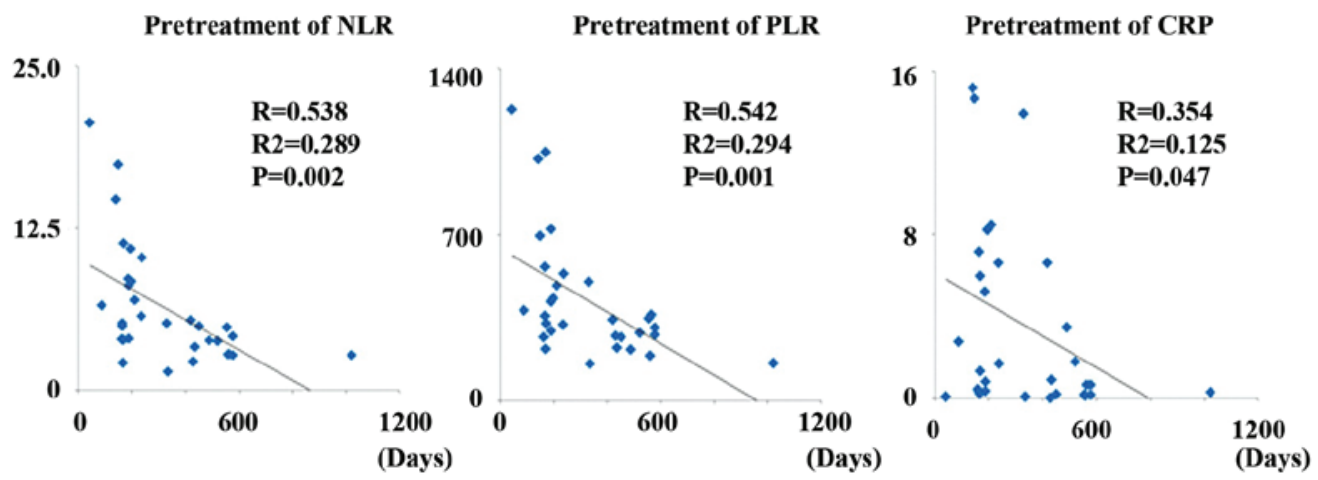

B

Pretreatment of NLR

Pretreatment of PLR

Pretreatment of CRP
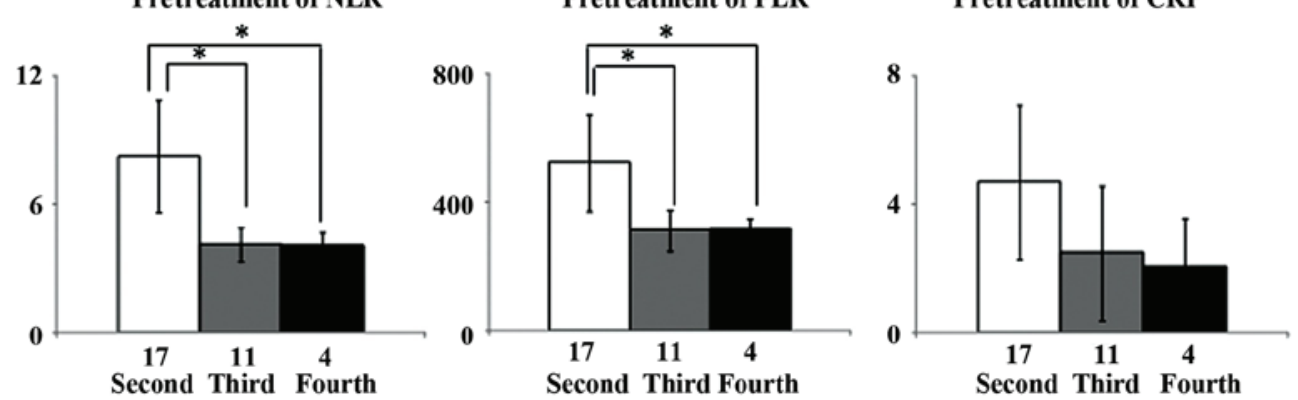

Figure 2. (A) Regression analysis for pretreatment neutrophil-lymphocyte ratio (NLR), platelet-lymphocyte ratio (PLR), C-reactive protein (CRP) and survival days in 32 patients whose cervical cancer recurred following first-line concurrent chemoradiation therapy. (B) Pretreatment NLR, PLR and CRP for patients whose second- to fourth-line regimen was their final line of chemotherapy. ${ }^{*} \mathrm{P}<0.05$.
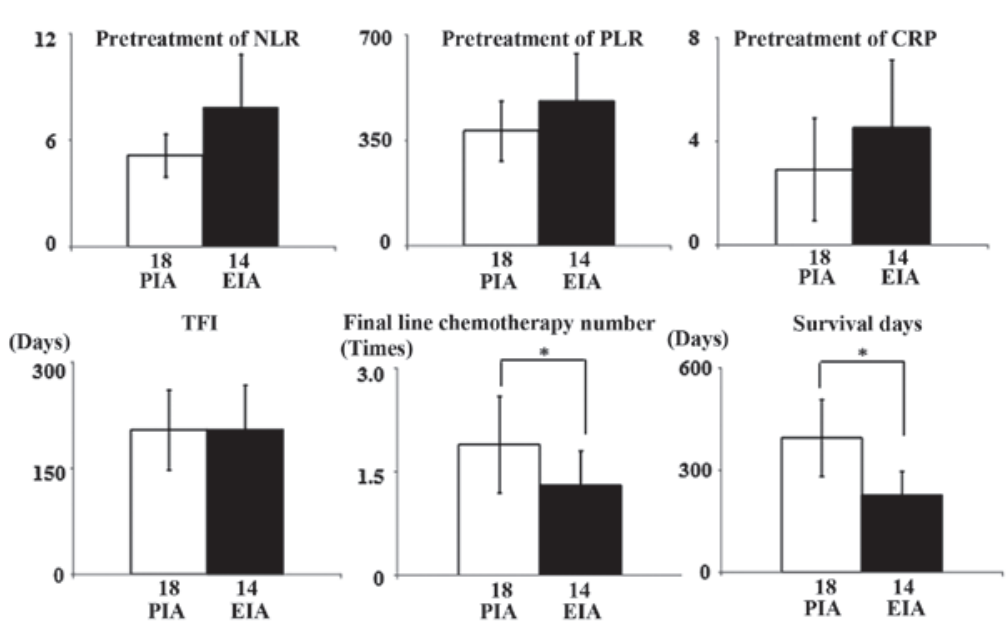

Figure 3. Pretreatment neutrophil-lymphocyte ratio (NLR), platelet-lymphocyte ratio (PLR), C-reactive protein (CRP), treatment-free interval (TFI), final-line chemotherapy number and survival days were compared with the extra- and prior-irradiation areas in patients whose cervical cancer recurred following first-line concurrent chemoradiation therapy. ${ }^{*} \mathrm{P}<0.05$. 
Table II. Prognostic factors for survival within 200 days according to Cox's univariate and multivariate analysis.

\begin{tabular}{|c|c|c|c|c|c|c|}
\hline & \multicolumn{3}{|c|}{ Univariate analysis } & \multicolumn{3}{|c|}{ Multivariate analysis } \\
\hline & Hazard ratio & $95 \% \mathrm{CI}$ & P-value & Hazard ratio & $95 \% \mathrm{CI}$ & P-value \\
\hline Histology (non-SCC) & 1.202 & $0.339-4.264$ & 0.776 & & & \\
\hline TFI ( $\leq 6$ months $)$ & 3.339 & $0.423-26.376$ & 0.253 & & & \\
\hline Extra-irradiation area & 4.187 & $1.431-12.248$ & $0.009^{\mathrm{a}}$ & 2.712 & $0.800-9.192$ & 0.109 \\
\hline $\begin{array}{l}\text { Second-line chemotherapy } \\
\text { as final line chemotherapy }\end{array}$ & 5.875 & $1.858-18.581$ & $0.003^{\mathrm{a}}$ & 3.071 & $0.840-11.229$ & 0.09 \\
\hline Pretreatment-NLR (>3.95) & 2.564 & $0.826-7.961$ & 0.103 & & & \\
\hline Pretreatment-PLR (>322.0) & 4.814 & $1.364-16.988$ & $0.015^{\mathrm{a}}$ & 4.204 & $1.158-15.268$ & $0.029^{\mathrm{a}}$ \\
\hline $\mathrm{CRP}(>0.7 \mathrm{mg} / \mathrm{dl})$ & 1.858 & $0.644-5.357$ & 0.252 & & & \\
\hline
\end{tabular}

${ }^{a} \mathrm{P}<0.05$. SCC, squamous cell carcinoma; TFI, treatment-free interval; NLR, neutrophil to lymphocyte ratio; PLR, platelet to lymhocyte ratio; CRP, C-reactive protein; CI, confidence interval.
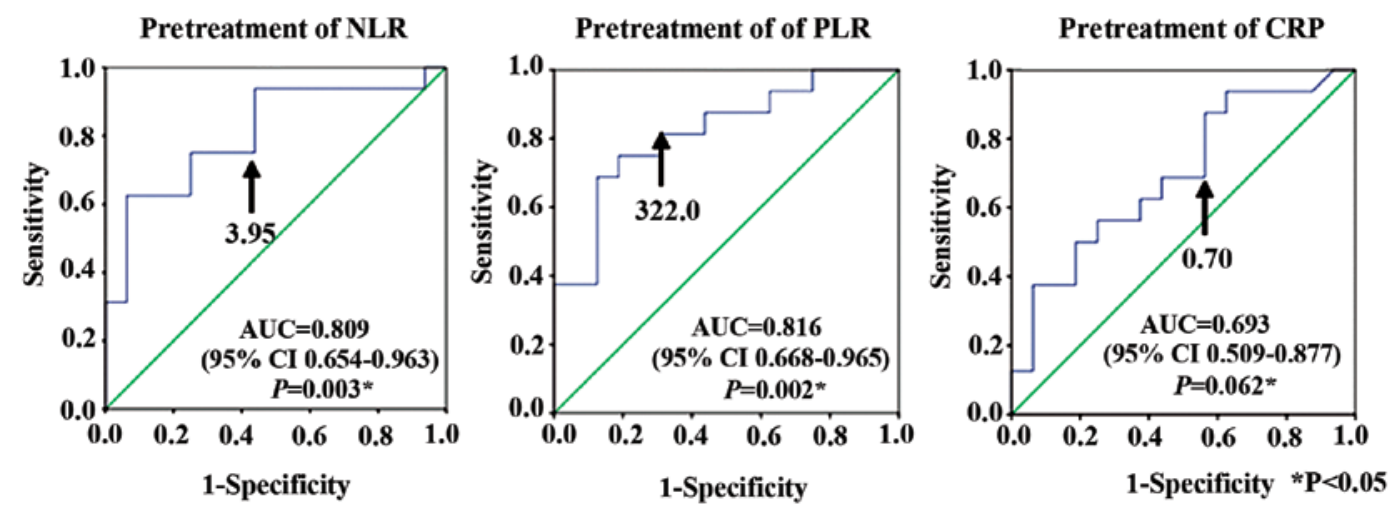

Figure 4. Receiver operating characteristic curves for optimal cut-off values to predict survival $<200$ days in patients whose cervical cancer recurred following first-line concurrent chemoradiation therapy, for pretreatment neutrophil-lymphocyte ratio (NLR) [3.95; area under the plasma-concentration curve (AUC), 0.809; 95\% confidence interval (CI), 0.654-0.963; $\mathrm{P}=0.003)$, platelet-lymphocyte ratio (PLR) (322.0; AUC, 0.816; 95\% CI, 0.668-0.965; $\mathrm{P}=0.002)$ and C-reactive protein (CRP) $(0.70 \mathrm{mg} / \mathrm{dl}$; AUC, 0.693; 95\% CI, 0.509-0.877; P=0.062)].

pretreatment PLR $>322.0(\mathrm{P}=0.015)$ with survival $<200$ days. Multivariate analyses showed that patients with high pretreatment PLR had a significantly higher hazard ratio (4.204) for survival $<200$ days compared to the patients with lower PLR $(\mathrm{P}=0.029)$ (Table II).

\section{Discussion}

Although treatment of recurrent cervical cancer depends on the site or extent of recurrence, disease-free interval and patient performance status $(13,14)$, this condition has no standard chemotherapy regimen. The previous RR and median overall survival (OS) for second-line monotherapy regimens were cisplatin $\left(50-100 \mathrm{mg} / \mathrm{m}^{2}\right)$ : $17-38 \%, 6.1-7.1$ months $(15,16)$; carboplatin (400 mg/m² every 4 weeks): $15-28 \%, 6.75$ months $(17,18)$; gemcitabine ( $800 \mathrm{mg} / \mathrm{m}^{2}$, days 1,8 and 15 every 4 weeks): 4.5-8\%, 4.9-6.5 (19,20); paclitaxel $\left(250 \mathrm{mg} / \mathrm{m}^{2}\right.$ every 3 weeks): $21-26 \%, 7.3$ months $(21,22)$; and irinotecan $\left(125 \mathrm{mg} / \mathrm{m}^{2} /\right.$ week for 4 weeks every 6 weeks or $350 \mathrm{mg} / \mathrm{m}^{2}$ every 3 weeks): $16-21 \%, 6.4-8.2$ months $(23,24)$. The previous RR and median OS for combination regimens were cisplatin $\left(75 \mathrm{mg} / \mathrm{m}^{2}\right)$ plus paclitaxel $\left(135-175 \mathrm{mg} / \mathrm{m}^{2}\right): 45-47 \%$, 7-10 months, more efficient than either of them used as single agents (25-27); and
CBDCA (AUC, 5) plus paclitaxel (135-175 mg/m²): 40-78\%, 9.6-13.0 months $(28,29)$. As carboplatin plus paclitaxel versus cisplatin plus paclitaxel regimens do not differ in terms of RR and OS (30), the side effects and anticancer agent continuations were considered in selecting weekly carboplatin plus paclitaxel for second-line regimens, irinotecan for third-line regimens, and gemcitabine for fourth-line regimens. In the present study, RR was $12.5 \%$ for second-line chemotherapy, $6.7 \%$ for third-line and $0.0 \%$ for fourth-line. Median survival was 198 days for the cohort, and 178.9, 483.0 and 493.5 days for patients whose final regimens were second-, third- and fourth-line chemotherapy, respectively, i.e., significantly shorter for patients whose final therapy was a second-line regimen.

Systemic inflammatory processes have been examined as possible predictors of prognosis in various types of cancer. Neutrophils release inflammatory cytokines and leukocytic and other phagocytic mediators that would induce damage to cellular DNA, inhibit apoptosis and promote angiogenesis $(31,32)$. Platelets can release potent mitogens or adhesive glycoprotein such as platelet-derived growth factor, transforming growth factor- $\beta$ and vascular endothelial growth factor (VEGF). Lymphocytes, such as cluster of differentiation $3^{+} \mathrm{T}$ cells and natural killer cells, can affect growth 
and metastasis $(33,34)$. CRP may be released as a result of producing inflammation-related cytokines, such as VEGF and interleukin-6 $(35,36)$. Thus, NLR and PLR have attracted the interest of investigators as possible markers of systemic inflammation, and therefore of prognosis. High pretreatment NLR and PLR have been reportedly associated with mortality in various types of cancer type (7-11). High pretreatment NLR is an independent indicator of poor prognosis in patients with cervical cancer $(37,38)$; and CRP levels are also a prognostic parameter in patients with cervical cancer (39).

However, to the best of our knowledge, no studies have previously reported the correlations between pretreatment NLR, PLR and CRP and the survival of patients with recurrent cervical cancer following first-line CCRT. In the present study, pretreatment NLR and PLR were significantly and inversely correlated with survival time in these patients. Furthermore, patients whose final regimen was second-line chemotherapy had significantly higher pretreatment NLR and PLR compared with those who survived to undergo third- and fourth-line chemotherapy. NLR, PLR, CRP, TFI, final-line chemotherapy and survival against recurrence sites were examined, and the patients whose recurrence spread to extra-irradiation areas had a significantly shorter survival rate compared with those whose tumors recurred in the prior-irradiation area. Higher inflammatory markers (NLR, PLR and CRP) were associated, but not significantly so, with recurrence sites.

One of the aims of the present study was to confirm whether pretreatment NLR, PLR or CRP could predict survival $<200$ days. ROC curve analyses showed that the optimal cut-off pretreatment values were NLR, 3.95; PLR, 322.0; and CRP, $0.70 \mathrm{mg} / \mathrm{dl}$. Univariate and multivariate analyses were significantly associated with pretreatment PLR >322.0 with survival $<200$ days.

The study has certain limitations; including relatively few patients, followed up over a relatively short period. Further prospective studies with more patients and longer follow-up periods would verify the present findings and clarify their significance.

In conclusion, the present findings suggest that pretreatment PLR is an important predictor of prognosis in patients with recurrent cervical cancer following CCRT.

\section{References}

1. Parkin DM, Bray F, Ferlay J and Pisani P: Global cancer statistics, 2002. CA Cancer J Clin 55: 74-108, 2005.

2. Chemoradiotherapy for Cervical Cancer Meta-Analysis Collaboration: Reducing uncertainties about the effects of chemoradiotherapy for cervical cancer: A systematic review and meta-analysis of individual patient data from 18 randomized trials. J Clin Oncol 26: 5802-5812, 2008.

3. Green JA, Kirwan JM, Tierney JF, Symonds P, Fresco L, Collingwood M and Williams CJ: Survival and recurrence after concomitant chemotherapy and radiotherapy for cancer of the uterine cervix: A systematic review and meta-analysis. Lancet 358: 781-786, 2001.

4. Quinn MA, Benedet JL, Odicino F, Maisonneuve P, Beller U, Creasman WT, Heintz AP, Ngan HY and Pecorelli S: Carcinoma of the cervix uteri. Int J Gynaecol Obstet 95 (Suppl 1): S43-S103, 2006.

5. Lee Y, Kim SH, Han JY, Kim HT, Yun T and Lee JS: Early neutrophil-to-lymphocyte ratio reduction as a surrogate marker of prognosis in never smokers with advanced lung adenocarcinoma receiving gefitinib or standard chemotherapy as first-line therapy. J Cancer Res Clin Oncol 138: 2009-2016, 2012.
6. Balkwill $\mathrm{F}$ and Mantovani A: Inflammation and cancer: Back to Virchow? Lancet 357: 539-545, 2001.

7. Aliustaoglu M, Bilici A, Seker M, Dane F, Gocun M, Konya V, Ustaalioglu BB and Gumus M: The association of pre-treatment peripheral blood markers with survival in patients with pancreatic cancer. Hepatogastroenterology 57: 640-645, 2010.

8. Azab B, Bhatt VR, Phookan J, Murukutla S, Kohn N, Terjanian T and Widmann WD: Usefulness of the neutrophil-to-lymphocyte ratio in predicting short- and long-term mortality in breast cancer patients. Ann Surg Oncol 19: 217-224, 2012.

9. Kishi Y, Kopetz S, Chun YS, Palavecino M, Abdalla EK and Vauthey JN: Blood neutrophil-to-lymphocyte ratio predicts survival in patients with colorectal liver metastases treated with systemic chemotherapy. Ann Surg Oncol 16: 614-622, 2009.

10. Sarraf KM, Belcher E, Raevsky E, Nicholson AG, Goldstraw P and Lim E: Neutrophil/lymphocyte ratio and its association with survival after complete resection in non-small cell lung cancer. J Thorac Cardiovasc Surg 137: 425-428, 2009.

11. Yamanaka T, Matsumoto S, Teramukai S, Ishiwata R, Nagai Y and Fukushima M: The baseline ratio of neutrophils to lymphocytes is associated with patient prognosis in advanced gastric cancer. Oncology 73: 215-220, 2007.

12. Wang CS and Sun CF: C-reactive protein and malignancy: Clinico-pathological association and therapeutic implication. Chang Gung Med J 32: 471-482, 2009.

13. Kesic V: Management of cervical cancer. Eur J Surg Oncol 32: 832-837, 2006.

14. Cadron I, Van Gorp T, Amant F, Leunen K, Neven P and Vergote I: Chemotherapy for recurrent cervical cancer. Gynecol Oncol 107 (Suppl 1): S113-S118, 2007.

15. Bonomi P, Blessing JA, Stehman FB, DiSaia PJ, Walton L and Major FJ: Randomized trial of three cisplatin dose schedules in squamous-cell carcinoma of the cervix: A Gynecologic Oncology Group study. J Clin Oncol 3: 1079-1085, 1985.

16. Thigpen JT, Blessing JA, Fowler WC Jr and Hatch K: Phase II trials of cisplatin and piperazinedione as single agents in the treatment of advanced or recurrent non-squamous cell carcinoma of the cervix: A Gynecologic Oncology Group Study. Cancer Treat Rep 70: 1097-1100, 1986.

17. Arseneau J, Blessing JA, Stehman FB and McGehee R: A phase II study of carboplatin in advanced squamous cell carcinoma of the cervix (a Gynecologic Oncology Group Study). Invest New Drugs 4: 187-191, 1986.

18. McGuire WP III, Arseneau J, Blessing JA, DiSaia PJ, Hatch KD, Given FT Jr, Teng NN and Creasman WT: A randomized comparative trial of carboplatin and iproplatin in advanced squamous carcinoma of the uterine cervix: A Gynecologic Oncology Group study. J Clin Oncol 7: 1462-1468, 1989.

19. Schilder RJ, Blessing JA, Morgan M, Mangan CE and Rader JS: Evaluation of gemcitabine in patients with squamous cell carcinoma of the cervix: A Phase II study of the gynecologic oncology group. Gynecol Oncol 76: 204-207, 2000.

20. Schilder RJ, Blessing J and Cohn DE: Evaluation of gemcitabine in previously treated patients with non-squamous cell carcinoma of the cervix: A phase II study of the Gynecologic Oncology Group. Gynecol Oncol 96: 103-107, 2005.

21. Kudelka AP, Winn R, Edwards CL, Downey G, Greenberg H, Dakhil SR, Freedman RS, Loyer E, Rusinkiewicz J, Gacrama P, et al: Activity of paclitaxel in advanced or recurrent squamous cell cancer of the cervix. Clin Cancer Res 2: 1285-1288, 1996.

22. Kudelka AP, Winn R, Edwards CL, Downey G, Greenberg H, Dakhil SR, Freedman RS, LoCoco S, Umbreit J, Delmore JE, et al: An update of a phase II study of paclitaxel in advanced or recurrent squamous cell cancer of the cervix. Anticancer Drugs 8: 657-661, 1997.

23. Verschraegen CF, Levy T, Kudelka AP, Llerena E, Ende K, Freedman RS, Edwards CL, Hord M, Steger M, Kaplan AL, et al: Phase II study of irinotecan in prior chemotherapy-treated squamous cell carcinoma of the cervix. J Clin Oncol 15: 625-631, 1997.

24. Lhommé C, Fumoleau P, Fargeot P, Krakowski Y, Dieras V, Chauvergne J, Vennin P, Rebattu P, Roche H, Misset JL, et al: Results of a European Organization for Research and Treatment of Cancer/Early Clinical Studies Group phase II trial of first-line irinotecan in patients with advanced or recurrent squamous cell carcinoma of the cervix. J Clin Oncol 17: 3136-3142, 1999.

25. Rose PG, Blessing JA, Gershenson DM and McGehee R: Paclitaxel and cisplatin as first-line therapy in recurrent or advanced squamous cell carcinoma of the cervix: A gynecologic oncology group study. J Clin Oncol 17: 2676-2680, 1999. 
26. Papadimitriou CA, Sarris K, Moulopoulos LA, Fountzilas G, Anagnostopoulos A, Voulgaris Z, Gika D, Giannakoulis N, Diakomanolis E and Dimopoulos MA: Phase II trial of paclitaxel and cisplatin in metastatic and recurrent carcinoma of the uterine cervix. J Clin Oncol 17: 761-766, 1999.

27. Piver MS, Ghamande SA, Eltabbakh GH and O'Neill-Coppola C: First-line chemotherapy with paclitaxel and platinum for advanced and recurrent cancer of the cervix - a phase II study. Gynecol Oncol 75: 334-337, 1999.

28. Tinker AV, Bhagat K, Swenerton KD and Hoskins PJ: Carboplatin and paclitaxel for advanced and recurrent cervical carcinoma: The British Columbia Cancer Agency experience. Gynecol Oncol 98: 54-58, 2005.

29. Pectasides D, Fountzilas G, Papaxoinis G, Pectasides E, Xiros N, Sykiotis C, Koumarianou A, Psyrri A, Panayiotides J and Economopoulos T: Carboplatin and paclitaxel in metastatic or recurrent cervical cancer. Int J Gynecol Cancer 19: 777-781, 2009.

30. Saito I, Kitagawa R, Fukuda H, Shibata T, Katsumata N, Konishi I, Yoshikawa $\mathrm{H}$ and Kamura T: A phase III trial of paclitaxel plus carboplatin versus paclitaxel plus cisplatin in stage IVB, persistent or recurrent cervical cancer: Gynecologic Cancer Study Group/Japan Clinical Oncology Group Study (JCOG0505). Jpn J Clin Oncol 40: 90-93, 2010.

31. Jackson JR, Seed MP, Kircher CH, Willoughby DA and Winkler JD: The codependence of angiogenesis and chronic inflammation. FASEB J 11: 457-465, 1997.

32. Grivennikov SI, Greten FR and Karin M: Immunity, inflammation, and cancer. Cell 140: 883-899, 2010
33. Assoian RK and Sporn MB: Type beta transforming growth factor in human platelets: Release during platelet degranulation and action on vascular smooth muscle cells. J Cell Biol 102: 1217-1223, 1986.

34. Kaplan KL, Broekman MJ, Chernoff A, Lesznik GR and Drillings M: Platelet alpha-granule proteins: Studies on release and subcellular localization. Blood 53: 604-618, 1979.

35. Hefler LA, Zeillinger R, Grimm C, Sood AK, Cheng WF, Gadducci A, Tempfer CB and Reinthaller A: Preoperative serum vascular endothelial growth factor as a prognostic parameter in ovarian cancer. Gynecol Oncol 103: 512-517, 2006.

36. Tempfer C, Zeisler H, Sliutz G, Haeusler G, Hanzal E and Kainz C: Serum evaluation of interleukin 6 in ovarian cancer patients. Gynecol Oncol 66: 27-30, 1997.

37. Lee YY, Choi CH, Kim HJ, Kim TJ, Lee JW, Lee JH, Bae DS and Kim BG: Pretreatment neutrophil:lymphocyte ratio as a prognostic factor in cervical carcinoma. Anticancer Res 32: 1555-1561, 2012

38. Zhang Y, Wang L, Liu Y, Wang S, Shang P, Gao Y and Chen X: Preoperative neutrophil-lymphocyte ratio before platelet-lymphocyte ratio predicts clinical outcome in patients with cervical cancer treated with initial radical surgery. Int J Gynecol Cancer 24: 1319-1325, 2014.

39. Polterauer S, Grimm C, Tempfer C, Sliutz G, Speiser P, Reinthaller A and Hefler LA: C-reactive protein is a prognostic parameter in patients with cervical cancer. Gynecol Oncol 107: 114-117, 2007. 